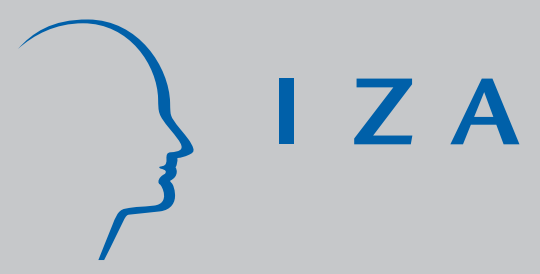

IZA DP No. 2403

\title{
The Effects of Globalization on Worker Training
}

Hans Gersbach

Armin Schmutzler

October 2006 


\title{
The Effects of Globalization on Worker Training
}

\author{
Hans Gersbach \\ ETH Zurich and IZA Bonn
}

\section{Armin Schmutzler}

University of Zurich

\section{Discussion Paper No. 2403 \\ October 2006}

\author{
IZA \\ P.O. Box 7240 \\ 53072 Bonn \\ Germany \\ Phone: +49-228-3894-0 \\ Fax: +49-228-3894-180 \\ E-mail: iza@iza.org
}

\begin{abstract}
Any opinions expressed here are those of the author(s) and not those of the institute. Research disseminated by IZA may include views on policy, but the institute itself takes no institutional policy positions.

The Institute for the Study of Labor (IZA) in Bonn is a local and virtual international research center and a place of communication between science, politics and business. IZA is an independent nonprofit company supported by Deutsche Post World Net. The center is associated with the University of Bonn and offers a stimulating research environment through its research networks, research support, and visitors and doctoral programs. IZA engages in (i) original and internationally competitive research in all fields of labor economics, (ii) development of policy concepts, and (iii) dissemination of research results and concepts to the interested public.
\end{abstract}

IZA Discussion Papers often represent preliminary work and are circulated to encourage discussion. Citation of such a paper should account for its provisional character. A revised version may be available directly from the author. 
IZA Discussion Paper No. 2403

October 2006

\section{ABSTRACT}

\section{The Effects of Globalization on Worker Training*}

We consider a three-stage game to examine how market integration affects firms' incentives to provide general worker training. In stage 1, firms invest in productivity-enhancing training. In stage 2, they can make wage offers for each others' workers. Finally, Cournot competition takes place. When two product markets become integrated, that is, replaced by a market with greater demand and more firms, training by each firm increases, provided the two markets are initially sufficiently concentrated. When barriers between less concentrated markets are eliminated, training is reduced. Integration increases welfare if it does not reduce training. However, for large parameter regions, welfare decreases if integration reduces training. We also show that opening product markets to countries with publicly funded training or cheap, low-skilled labor can threaten apprenticeship systems.

JEL Classification: D43, J24

Keywords: general worker training, human capital, oligopoly, turnover, globalization

Corresponding author:

Armin Schmutzler

Socioeconomic Institute

University of Zurich

Blümlisalpstr. 10

8006 Zurich

Switzerland

E-mail:arminsch@soi.unizh.ch

\footnotetext{
* We are grateful to Alexandrina Braack, Verena Liessem, Jan Rose Skaksen, Manfred Stadler and seminar participants in Zurich, at the EEA meeting in Amsterdam, the IO panel of the Verein für Socialpolitik (Mannheim 2005) and the IZA Conference on "Globalization - Implications for Labour Market and Welfare Policies" (Aarhus, Denmark, 2004) for their helpful comments.
} 


\section{Introduction}

Though simple theory would suggest otherwise, many empirical studies show that firms finance a considerable part of general worker training. However, the level of general worker training has decreased recently in some countries, including Germany. For instance, between 1985 and the turn of the century, the number of apprentices in West Germany declined by almost 30 percent. Part of this decline can be attributed to the reduction in population in the relevant age brackets and to increasing levels of university-entrance qualification. ${ }^{1}$ However, much of the decline cannot be easily explained. In this paper we offer an alternative explanation. We suggest that the decline may be related to the increasing integration of German product markets into the European and World economy which has taken place over the last decades.

Two simple ideas are the basis for this hypothesis. First, we think of general training expenses as cost-reducing investments, as training increases worker productivity. Second, when product markets are imperfectly competitive, their integration increases competition. Using these ingredients, we show that product market integration may reduce the training investments of firms, ultimately leading to a collapse of general training.

To this end, we develop a model where firms can invest in productivityenhancing general training in a first stage. Then they make wage offers for each others' trained workers. Finally, product-market competition takes place. $^{2}$ When two product markets become integrated, that is, replaced by a single market, there are three effects on firms' incentives to train their workers. First, the market size increases, which raises each firms' incentives to invest in training. Second, the number of competitors increases, which reduces training investments. Third, competition for trained workers increases, which tends to raise their wage and make training less attractive. We show

\footnotetext{
${ }^{1}$ See, for example, Euwals and Winkelmann 2001, Franz and Soskice 1995, Büchel 2002.

${ }^{2}$ To simplify the exposition, our treatment in the main text supposes that integration does not affect the total number of firms in the world market. In the appendix, we show how this condition can be endogenized when firms make entry and exit decisions.
} 
that these interrelated effects cause a hump-shaped pattern of training incentives in a Cournot framework. If the national product markets are relatively small and populated by few firms, integration will foster training. The opposite occurs when larger product markets with a higher number of firms integrate.

The effects of integration on welfare are striking. Integration has unambiguously positive effects on welfare if it does not affect training decisions. If integration induces a training equilibrium, then this statement still holds. However, if integration destroys the training equilibrium, it reduces welfare for a large set of parameters. Intuitively, even though integration reduces mark-ups and leads to savings in training costs, the negative welfare effects due to lower productivity dominate.

In addition to product market integration, we also consider labor market integration. At first glance, when workers face more options concerning future employers, the willingness of firms to train their workers should be reduced. However, we show that, at least in our setting, labor market integration usually has no effect on training decisions.

Finally, we apply our analysis to countries facing competition in product markets from countries with alternative training institutions. For example, countries with apprenticeship systems, such as Germany, face competition from firms from countries with vocational schooling systems or countries with low-skill workers. We show that such competition is indeed a threat to apprenticeship systems: The negative effects of globalization on training are more pronounced than when countries are symmetric.

Existing theoretical papers on the relation between globalization and human capital accumulation concentrate on workers' incentives to acquire human capital, arguing that globalization affects both workers' returns to education and its costs. This literature is quite optimistic about the effects of globalization on human capital accumulation. Several authors focus on the situation in developing countries. For instance, Cartiglia (1997) emphasizes that, because trade has income effects, it relaxes the liquidity constraints 
that workers are facing, and thus their ability to invest in education. Further, he notes that by increasing the relative wages of skilled workers, trade openness increases the costs of education. Another important aspect is the role of knowledge flows to developing countries which foster learning and skill accumulation. For example, Pissarides (1997) argues that trade involves technology transfer from industrial to developing countries which is biased towards skilled labor, leading at least to temporary increases in the demand for skilled labor. Chuang (1998) argues that exports themselves promote learning. Other papers are more pessimistic. On the basis of a Heckscher-Ohlin model, Wood and Ridao-Cano (1999) show that, in developing countries, where skilled labor is relatively scarce, the opening of the world market reduces the incentive to invest in skills relative to developed countries. $^{3}$

Contrary to the above literature, other authors deal with effects of globalization that are similar in industrialized countries and the developing world, distinguishing explicitly between firm-specific and general training. For instance, Rodrik (1997) argues that uncertainty about sector-specific shocks brought about by globalization may reduce the incentives to acquire sectorspecific skills. General human capital investment, on the other hand, allows workers to adjust easily to sectoral shocks (Kim and Kim, 2000).

To sum up, the theoretical literature suggest that globalization tends to support human capital investment through various channels, though there may be differential effects on different countries. The empirical literature on the subject is not yet very well developed. Though some authors have found positive effects of some aspects of globalization on the differential between wages for skilled and unskilled labor, the evidence is far from conclusive. For instance, contrary to other authors (e.g., Katz and Autor 1999), Feenstra and Hanson (2001) conclude that, like skill-biased technological change, international input trade increases the wage premium for skilled labor. Us-

\footnotetext{
${ }^{3}$ A negative relation between openness and human-capital investments has also been postulated by Findlay and Kierzkowski (1983) and Stokey (1991).
} 
ing data for Taiwan, Chuang (2000) argues that export growth promotes human-capital investment. Most importantly in our context, there is no clear evidence on the relation between globalization and firms' investments in general human capital, in particular, no support of the argument based on Rodrik (1997) and Kim and Kim (2000) that globalization supports general training.

Like these authors, we consider those effects of integration that concern industrialized and developing countries in a similar way. Also, we focus on general training and specifically, on firms' incentives to finance such training. In this respect, our paper relates to theories explaining why firms invest in general training at all, even though, according to Becker (1964) and Mincer (1974), at least in competitive labor markets, they should have no incentive to bear the costs of general training, as the associated rents accrue exclusively to the employees. ${ }^{4}$ This literature does not, however, discuss the role of product market competition or globalization on training decisions. ${ }^{5}$

The paper is organized as follows. Section 2 analyzes the model with immobile workers. Section 3 introduces the model with mobile workers, and provides reduced form conditions for training equilibria. Section 4 analyzes how globalization, that is, labor and/or product market integration, affects the chances that training equilibria will arise. In Section 5 we explore the effects of globalization on welfare and distribution. Section 6 extends the analysis to countries with asymmetric training systems. Section 7 concludes and discusses extensions. Apart from containing proofs and useful formulas, the appendix also deals with the extension of the approach to endogenous numbers of firms.

\footnotetext{
${ }^{4}$ Examples include Katz and Ziderman (1990), Chang and Wang (1995, 1996), Abe (1994), Prendergast (1992), Glaeser (1992), Acemoglu (1997) and Acemoglu and Pischke (1998). Acemoglu and Pischke (1999) provide an insightful survey of the arguments.

${ }^{5}$ Gersbach and Schmutzler (2003) consider the effects of product market competition on training incentives in a duopolistic setting: To analyze the effects of globalization, we have to extend their model to arbitrary firm numbers.
} 


\section{The Model with Immobile Workers}

We first introduce the Immobile-Worker Game (IWG) as a reference model. For ease of exposition, we suppose that the number of firms is fixed. In Appendix 1, we show how this condition can be derived endogenously if firms can enter or exit the market depending on market conditions.

In the first stage, firms $i=1, \ldots, I$ simultaneously choose their general human capital investment levels $g_{i} \in\{0,1\} .{ }^{6}$ Marginal costs $c_{i}$ are a decreasing function $c\left(g_{i}\right)$ of the number of trained workers in a firm. Training costs are $T>0$ for a firm. ${ }^{7}$ In the second stage, the $I$ firms are Cournot competitors, producing homogeneous goods, with inverse demand $p=a-\frac{B}{I} x$, where $x$ is output, $p$ is price and $a$ and $B$ are positive constants. Applying standard formulas for Cournot competition with heterogeneous firms, profits of firm $i$ are

$$
\pi_{i}=\frac{I}{B(I+1)^{2}}\left(a-I c_{i}+\sum_{j \neq i} c_{j}\right)^{2} .
$$

Also, for later reference, note that the equilibrium price is

$$
p=\frac{1}{(I+1)}\left(a+\sum_{j=1}^{I} c_{j}\right) .
$$

To illustrate our results, we use the specific training technology given by ${ }^{8}$

$$
c_{i}\left(g_{i}\right)=\frac{c}{\delta g_{i}+1} \text { for some } \delta>0, g_{i} \in\{0,1\} .
$$

\footnotetext{
${ }^{6}$ It is best to think of firms as either having one worker each or a team of workers such that their human capital investments are perfect complements, education is only valuable if the entire team is educated.

${ }^{7}$ We interpret training costs in a broad sense. They consist of all expenses, that is, to upgrade the skills of workers, including any measures to motivate workers to acquire skills.

${ }^{8} \mathrm{We}$ assume that the marginal costs are lowered by trained individuals for the entire range of quantity choices that are relevant for the derivation of equilibria. The assumption requires that high- and low-skilled workers are complementary in the production process (see Teulings 2000 and Acemoglu 2001).
} 
Using (1) and (3), profits of firm $i$ are:

$$
\pi_{i}\left(g_{i}, G ; I\right)=\frac{I}{B(I+1)^{2}}\left(a-\frac{c I}{\delta g_{i}+1}+\frac{\left(G-g_{i}\right) c}{\delta+1}+\left(I-1-G+g_{i}\right) c\right)^{2}
$$

where $G$ is the total number of firms who train their workers. For the training incentives for a firm when all of its competitors also train their workers, we write:

$$
\Delta \pi(I) \equiv \pi_{i}(1, I ; I)-\pi_{i}(0, I-1 ; I) .
$$

The condition required for a symmetric training equilibrium is obvious.

Proposition 1 A training equilibrium in the $I W G$ with $g_{i}=1, i=1, \ldots, I$ exists if and only if $\Delta \pi(I) \geq T$.

Proposition (1) and condition (4) imply

$$
\Delta \pi(I)=\frac{\delta c I^{2}}{B(I+1)^{2}(1+\delta)^{2}}\{2(a-c)(1+\delta)-(I-2) \delta c\}
$$

Corollary 1 In the IWG, $\Delta \pi(I)$ is single-peaked.

Proof. See Appendix 2.

Figure 1 plots $\Delta \pi(I)$ for $a=10, c=1, B=1, \delta=0.9$.

We now think of integration of two identical countries, each with $I=J$ firms; $J>1$. Thus, the number of firms in the world market is $I=2 J .^{9}$ Using the lemma, it is clear that the effects of integration on training depend on the relative sizes of $\Delta \pi(J)$ and $\Delta \pi(2 J)$. Given the hump-shape of $\Delta \pi$, integration tends to induce more training for relatively low values of $J$ and less training for relatively high values.

- Figure 1 about here -

\footnotetext{
${ }^{9}$ Note the logic of the notation that we apply throughout the paper: $I$ stands for the number of firms active in the product market, which may be the world market or a national market; when we consider one out of two symmetric countries, we use $I=J$.
} 
This pattern occurs repeatedly in this paper: If the two markets are sufficiently concentrated the positive effects of integration on training that stem from greater market size dominate over the negative effects from greater competition. ${ }^{10}$ For less concentrated markets, the training equilibrium is destroyed by product market integration. With an endogenous number of firms, as laid out in Appendix 1, the positive effects of integration on training would thus dominate when entry costs are high and demand is low.

\section{Mobile Workers}

Worker mobility can potentially affect the relation between globalization and training through two channels. First, even mobility within countries is likely to affect training behavior, because firms have to take into account the possibility that competitors might poach trained workers. As this possibility tends to reduce training levels both before and after integration, it is thus unclear without further analysis how intra-country mobility influences the effects of product market integration on training. Second, mobility between countries is in itself worth studying. How does such mobility affect training incentives? Intuitively, training incentives might be reduced, because firms face a greater danger that competitors can poach trained workers. We check whether this intuition is correct.

As in the IWG, we shall assume that integration does not affect the total number of firms. A justification of this assumption along the lines of Lemma 3 in Appendix 1 is possible, assuming that the costs of entry are sunk and the fixed costs of production are negligible.

\footnotetext{
${ }^{10} \mathrm{To}$ isolate the effects of increasing market size and increasing firm number, consider a model with firm number $I^{F}$ and market size $I^{M}$. Suppose $c_{j}=\frac{c}{1+\delta}$ for all $j \neq i$. Expression (1) becomes $\pi_{i}=\frac{I^{M}}{B\left(I^{F}+1\right)^{2}}\left(a-I^{F} c_{i}+\sum_{j=1, j \neq i}^{I^{F}} c_{j}\right)^{2}$. Thus, $\Delta \pi$ is always increasing in $I^{M}$, but decreasing in $I^{F}$ when $c_{i}>c$.
} 


\subsection{The Game Structure}

In the Mobile-Worker Game (MWG), as in the IWG, firms take training decisions $g_{i} \in\{0,1\}$ in the first stage. In the second stage, after having observed each others' training decisions, firms $i \in\{1, \ldots, I\}$ simultaneously offers wages $w_{i j}, j \in\{1, \ldots, I\}$ for all the trained workers in the market. ${ }^{11}$ If $g_{j}=0$, wages will be $w_{i j}=0, i=1 \ldots I$. Thus, (i) we normalize the wages of workers without training to zero; (ii) we assume that the wage of a worker without training is also the reservation wage for the trained workers, that is, their knowledge is useless outside the industry under consideration. After having obtained the wage offers, each employee accepts the highest offer. ${ }^{12}$ Denote the number of trained workers in firm $i$ at the end of the second stage as $t_{i}$. Recall that $G$ is the total number of trained workers in period 1 , which is the same as the total number of firms that train their workers. Hence $G=\sum_{i=1}^{n} t_{i}$. As firms can now have more than one trained worker, we need to define the cost function more generally than in the IWG as

$$
c\left(t_{i}\right)=\frac{c}{\delta t_{i}+1} \text { for some } \delta>0 .
$$

In the third stage, Cournot competition takes place. Gross profits depend on marginal costs, as in (1). Using (6), gross profits are therefore functions $\tilde{\pi}_{i}\left(t_{1}, \ldots, t_{I} ; I\right)$ of the distribution of trained workers after the poaching game. As $t_{j}$ can now be greater than 1 , the distribution of workers across competitors is not necessarily uniform and the notation $\pi_{i}\left(t_{i}, G ; I\right)$ is no longer well-defined, unless we apply the following conventions:

\footnotetext{
${ }^{11}$ Here "wages" should be interpreted broadly, including any type of non-monetary benefits such as pleasant working environments, fringe benefits and flexible working hours which involve costs for the employer. A priori we allow wages to differ even for individuals who have the same level of human capital or belong to the same firm.

${ }^{12} \mathrm{As}$ a tie-breaking rule, we use the convention that the employee stays with his original firm if this firm offers the highest wages. Moreover, the turnover game has the structure of an auction with externalities where multiple auctioneers (the workers) auction themselves to multiple bidders (the firms).
} 
(i) If $G-t_{i} \leq I-1, \pi_{i}\left(t_{i}, G ; I\right)$ refers to the case that every competitor of firm $i$ has at most one trained worker.

(ii) If $G-t_{i}>I-1$ or equivalently if $t_{i}=0$ and $G=I, \pi_{i}\left(t_{i}, G ; I\right)$ refers to the case that one firm has two trained workers while all other competitors of firm $i$ have one worker.

- Table 1 about here -

We summarize the game in Table 1 . We distinguish between net profits and gross profits, according to whether or not wages for trained workers are deducted. We define the long-term payoff as the difference between net profits and training expenses. Finally, we define the product market subgames as the subgames starting in Period 3 and the turnover subgames as the subgames starting in Period 2. To simplify the notation further, we often neglect the index $i$ in the profit variable and write $\pi\left(t_{i}, G ; I\right)$.

\subsection{Sufficient Conditions for Training - Overview}

We first consider sufficient conditions for a training equilibrium $\left(g_{1}, \ldots, g_{I}\right)=$ $(1, \ldots, 1)$. Necessary conditions are harder to establish, and they will be discussed in Appendix 4. We first sketch how we arrive at sufficient conditions. Later, we shall fill in the details.

For $t_{i} \in\{2, \ldots, G\}$, define

$$
A P\left(t_{i}, G ; I\right) \equiv \frac{\pi\left(t_{i}, G ; I\right)-\pi(1, G ; I)}{t_{i}-1} .
$$

Starting from a situation where all firms have one trained worker, $A P\left(t_{i}, G ; I\right)$ is the average productivity of each of the $t_{i}-1$ workers that a firm poaches in the turnover stage. From a firm's point of view, the positive productivity effect of poaching also consists of the negative effect imposed on the competitor: As (1) shows, poaching increases profit by reducing its costs and by increasing its competitors' costs. Similarly, define

$$
M P\left(t_{i}, G ; I\right)=\pi\left(t_{i}+1, G ; I\right)-\pi\left(t_{i}, G ; I\right)
$$


as the marginal productivity of poaching an additional worker for a firm that has $t_{i}$ of the $I$ workers in the market. We maintain the following assumptions.

\section{Assumption 1}

$$
\begin{aligned}
\max _{t_{i} \in\{3, \ldots, I\}} A P\left(t_{i}, I ; I\right) & \leq M P(1, I ; I) \\
\max _{t_{i} \in\{2, \ldots, I-1\}} A P\left(t_{i}, I-1 ; I\right) & \leq M P(0, I-1 ; I)
\end{aligned}
$$

The assumption clearly holds if the marginal productivity of poaching is decreasing in $t_{i}$. It will be useful for the analysis of the turnover subgames and the proof of our following main result:

Theorem 2 A training equilibrium exists if

$$
\begin{gathered}
\theta(I) \equiv 2 \pi(1, I ; I)-\pi(2, I ; I)-\pi(0, I-1 ; I) \geq T . \\
M P(0, I-1 ; I) \geq M P(1, I-1 ; I)
\end{gathered}
$$

For wide parameter ranges, Assumption 1 holds whenever conditions (11) and (12) are fulfilled. Intuitively, condition (11) implies

$$
\pi(1, I ; I)-\pi(0, I-1 ; I) \geq \pi(2, I ; I)-\pi(1, I ; I)
$$

and hence decreasing marginal returns to poaching. Condition (12) also reflects decreasing marginal returns, with $I-1$ rather than $I$. As Assumption 1 is implied by decreasing marginal returns, it is not surprising that it is typically implied by (11) and (12).

The proof of Theorem 2 will consist of the following steps.

1. Gross product market profits in a training equilibrium are $\pi(1, I ; I)$.

2. Proposition 2 below: If (11) holds and $I$ firms have trained their workers, there is an equilibrium of the ensuing turnover game where each firm retains its worker and pays $w^{*}=M P(1, I ; I)$. 
3. Proposition 3 below: If (12) holds and $I-1$ firms have trained their workers, there is an equilibrium of the ensuing turnover game where each of these firms retains its worker and obtains net profits $\pi(0, I-1 ; I)$.

4. The net training incentive, that is, the difference between net profits in the training equilibrium and net profits for a firm that deviates to "no training" is therefore given by $\theta(I)=\pi(1, I ; I)-M P(1, I ; I)-$ $\pi(0, I-1 ; I)$, so that $(11)$ implies the result.

We now fills in the gaps by proving Propositions 2 and 3 .

\subsection{The Turnover Equilibrium}

We first consider the subgame where all firms have trained their workers.

Proposition 2 Suppose each firm has trained one worker in period 1.

(a) Suppose

$$
M P(0, I ; I) \geq M P(1, I ; I) .
$$

Then there is an equilibrium of the turnover game where the highest wage offer for each worker is $w^{*}=M P(1, I ; I) .{ }^{13}$ In any equilibrium each firm employs exactly one trained worker.

(b) Suppose that condition (13) does not hold. Then, in any subgame perfect equilibrium in pure strategies, there is at least one firm without a trained worker. In equilibrium, this firm cannot have lower net profits than any firm with a trained worker.

Proof. See Appendix 2.

Because $\pi(0, I-1 ; I)>\pi(0, I ; I),(11)$ implies (13). Thus, step 2 above follows from Proposition 2. To see the intuition of Proposition 2, note that $w^{*}$ is the willingness of each firm to pay for a second worker. Condition (13)

\footnotetext{
${ }^{13}$ The equilibrium is supported by wage offers $w_{i j}=w^{*}, i=1, \ldots, I$ and $j=1, \ldots, I$, or alternatively, by wage offers $w^{*}$ to only two workers, i.e., $w_{i i}=w^{*}, w_{i i+1}=w^{*}$ for $i=1, \ldots, I-1$ and $w_{I 1}=w^{*}, w_{I I}=w^{*}$ and zero wage offers in all other cases.
} 
guarantees that, starting from an equal distribution of workers, the gains for a firm from attracting a worker $(M P(1, I ; I))$ are (weakly) smaller than the losses if a competitor attracts one of its worker $(M P(0, I ; I))$. Thus, each firm is willing to offer $w^{*}=M P(1, I ; I)$, and there is no turnover. By (9), it is not a profitable deviation to attract further workers from the competitors: Their average productivity is below the wage, which is the marginal productivity of the second worker. ${ }^{14}$

To analyze deviation incentives, we consider the subgame where one firm does not invest in training (step 3 above).

Proposition 3 Suppose that I-1 firms have trained their workers and (12) holds. Then, the resulting turnover game has an equilibrium where each worker receives a maximal wage offer of $w^{*}=M P(0, I-1 ; I)$ and $(I-1)$ firms employ exactly one worker. Accordingly, net profits for all firms are $\pi(0, I-1 ; I)$.

Proof. See Appendix 2.

As (12) is an assumption of our Theorem 2, step 3 above follows. Compared to the case where all firms have trained their workers, trained workers are now more valuable as they are relatively scarce. As a result, wages are higher: $M P(0, I-1 ; I)=\pi(1, I-1 ; I)-\pi(0, I-1 ; I)$ is bounded below by $\pi(1, I ; I)-\pi(0, I-1 ; I)$, which, in turn, is bounded below by $M P(1, I ; I)=\pi(2, I ; I)-\pi(1, I ; I)$ when (11) holds. Thus, by training, firms increase the supply of trained workers and thereby reduce their wages. As step 4 is obviously correct, this completes the proof of Theorem 2.

\subsection{Other Equilibria in Pure Strategies}

We first show that there is always an equilibrium without training.

\footnotetext{
${ }^{14}$ Note that Part (b) of Proposition 2 is not a full description of the turnover game. For our analysis, we do not require such a full solution which amounts to a tedious caseby-case discussion. For instance, for the case that $I$ is even, we calculated conditions for an equilibrium where half the firms have two workers each, but the others have none. Equilibrium wages are such that all firms have identical net profits.
} 
Proposition 4 The equilibrium $\left(g_{1}, \ldots, g_{I}\right)=(0, \ldots, 0)$ always exists.

Proof. See Appendix 2.

Intuitively, deviating from no training is unattractive, as the only firm with one trained worker faces the threat that the worker will move to a competitor. We next consider partial training equilibria, where some, but not all firms train.

Proposition 5 Suppose for $G \in\{1,2, \ldots, I-1\}$,

$$
\begin{gathered}
M P(0, G ; I) \geq M P(1, G ; I) ; \\
\max _{t_{i} \in\{2, \ldots, G\}} A P\left(t_{i}, G ; I\right) \leq M P(1, G ; I) .
\end{gathered}
$$

Then no equilibrium with $G$ trained workers exists. ${ }^{15}$

According to (14) and (15), a firm has at most one worker in the turnover game. Therefore, the net profits of a deviating firm are $\pi(0, G-1 ; I)$, whereas they are $\pi(0, G ; I)$ before deviation. Thus, even without accounting for training costs, deviation from a partial training equilibrium by not training is always profitable.

\section{The Effects of Globalization on Training}

We now analyze the effects of labor and product market integration on training behavior. In Section 4.1 we show how full integration of both product and labor markets affects training behavior. In 4.2, we consider pure labor market integration (with separated product markets).

\footnotetext{
${ }^{15}$ If condition (14) or (15) is violated, a partial training equilibrium still does not exist if an analogue of Condition (ICW) in Appendix 4 holds, with $I$ replaced by $G$.
} 


\subsection{Full Integration}

To analyze the effects of integrating both the labor and the product markets of two identical countries, we now compare the game of Section 3 for $I=J$ with the game for $I=2 J$. Figure 2 depicts net training incentives $\theta(I)$ for $a=10, B=1, c=1 .^{16}$

- Figure 2 about here -

For $\delta=0.1$ (lower curve), there is no value of $I$ for which $\theta(I)$ is positive. As $\delta$ increases, there is an intermediate range of $I$-values for which $\theta(I)$ is positive. This region is greater for $\delta=0.9$ than for $\delta=0.5$. In all three cases, training incentives are first increasing, then decreasing in $I$. This partly reflects the intuition from the IWG: The increasing demand following integration increases the returns to training, whereas the increasing number of competitors reduces the returns to training. In addition, however, there is an additional wage effect that is absent in the model with immobile workers. As we shall show in the next section, wages $w^{*}=\pi(2, I ; I)-\pi(1, I ; I)$ for trained workers are increasing in $I$, which tends to exacerbate the potential negative effects of integration on training incentives.

The patterns exposed in Figure 2 hold more generally: The net training incentives are typically hump-shaped. More precisely, consider the extension of $\theta(I)$ from $\{2,3, \ldots\}$ to the positive real numbers, defined by

$$
\theta(I)=\frac{I}{(I+1)^{2}}\left(\alpha I^{2}+\beta I+\gamma\right) \text { for constants } \alpha, \beta, \gamma \in \Re .
$$

Proposition $6 \theta(I)$ has the following properties.

(i) $\theta(0)=0$

(ii) $\lim _{I \rightarrow \infty} \theta(I)=-\infty$

(iii) $\theta(I)$ crosses the $I$-axis twice at most.

\footnotetext{
${ }^{16}$ We have compiled the relevant profit formulas in Appendix 3.
} 
Proof. See Appendix 2.

Figure 3 shows the implications of these properties for the effects of integration on training. For $J<I^{*}, \theta(J)<T$ and $\theta(2 J)<T$, so that the no-training equilibrium prevails before and after integration. For $I^{*}<J<$ $I^{* *}, \theta(J)<T$ and $\theta(2 J)>T$, so that integration induces training. For $I^{* *}<I<I^{* * *}, \theta(J)>T$ and $\theta(2 J)>T$, so that the training equilibrium prevails before and after integration. For $I^{* * *}<I<I^{* * * *}, \theta(J)>T$ and $\theta(2 J)<T$, so that integration destroys training. For $I>I^{* * * *}$, the no-training equilibrium prevails before and after integration. Therefore, integration has a positive effect on training if the markets are initially small and a negative effect if the markets are initially large. ${ }^{17}$

- Figure 3 about here -

\subsection{Pure Labor Market Integration}

We now sketch the effects of pure labor market integration without product market integration. We compare training incentives in the autarky models for $I \equiv J$ with those for the integrated labor market (ILM) game defined as follows.

In stage 1, firms in both countries make training decisions as in the MWG. In stage 2 , however, each firm makes wage offers to all trained workers in the two countries. In stage 3 , product market competition takes place in each country as in the MWG. For $t_{i} \in\{1, \ldots, J\}, t_{i}^{*} \in\{1, \ldots, J\}$, define

$$
A P\left(t_{i}, t_{i}^{*}, J ; J\right) \equiv \frac{\pi\left(t_{i}+t_{i}^{*}, J+t_{i}^{*} ; J\right)-\pi(1, J ; J)}{t_{i}+t_{i}^{*}-1}
$$

This expression is the average productivity per poached worker if firm $i$ has $t_{i}$ workers trained in its own country and $t_{i}^{*}$ workers trained abroad. In terms of their profit effects, foreign and home-country workers are not perfect substitutes, although trained workers generate the same cost reduction

\footnotetext{
${ }^{17}$ Note that, for other parameters, some of these intervals may be degenerate. For instance, if $T$ is high, there will be no training equilibrium independent of $J$.
} 
irrespective of the country where they received training. While hiring either type has a positive effect on a firm's efficiency, hiring a home-country worker also reduces the efficiency of a direct competitor.

Proposition 7 Suppose that in the ILM game each firm has trained one worker in period (1). Suppose the following conditions hold:

$$
\begin{gathered}
M P(0, J ; J) \geq M P(1, J ; J) ; \\
\max _{t_{i}, t_{i}^{*} \in\{1, \ldots, J\}} A P\left(t_{i}, t_{i}^{*}, J ; J\right) \leq M P(1, J ; J)
\end{gathered}
$$

Then there is an equilibrium of the turnover game where the highest wage offer for each worker is $w^{*}=M P(1, J ; J)$. In any equilibrium, each firm employs exactly one worker.

The proof is analogous to Proposition 2. The main difference is between (9) and the more restrictive condition (19): In the ILM model, each firm can also deviate by poaching abroad. However, poaching at home is more attractive because it raises rivals' costs. Thus a firm will only poach abroad if it already employs all home-country workers. As a consequence, the additional poaching opportunities with labor market integration are likely to be irrelevant, so that the difference between (9) and (19) does not matter.

Proposition 3 generalizes in an analogous fashion, assuming that $M P(0, J-1 ; J) \geq M P(1, J-1 ; J)$ and

$$
\max _{\substack{t_{i} \in\{1, \ldots, J\} \\ t_{i}^{*} \in\{1, \ldots, J\}}} A P\left(t_{i}, t_{i}^{*}, J-1 ; J\right) \leq M P(0, J-1 ; J)
$$

To sum up, after pure labor market integration, a training equilibrium exists under analogous conditions as under autarky, except that our maintained assumptions (9) and (10) have to be sharpened. This suggests that the effects of full integration are essentially the effects of product market rather than labor market integration. 


\section{Welfare and Distributional Effects of Full Integration}

\subsection{Preliminaries}

We now explore the welfare effects of full integration, that is, we compare welfare in the training game when $I=J$ with the case $I=2 J$. We assume inverse demand $p=a-\frac{B}{I} x$, and $\operatorname{costs} c\left(t_{i}\right)=\frac{c}{\delta t_{i}+1}$ for some $\delta>0 .{ }^{18}$

We define welfare $W_{I}$ as the sum of consumer surplus, producer surplus and workers' rents. Denote prices in the training and no training equilibrium as $P_{I}(T)$ and $P_{I}(0)$, respectively. Welfare in the no-training equilibrium is

$$
W_{I}^{N T} \equiv I \pi(0,0 ; I)+\int_{P_{I}(0)}^{a} X(p, I) d p=\frac{I(a-c)^{2}(I+2)}{B(I+1)^{2}}
$$

As the wages of trained workers enter the producer surplus negatively, they cancel out. Thus, in the training equilibrium, welfare is

$$
W_{I}^{T}=I \pi(1, I ; I)+\int_{P_{I}(T)}^{a} X(p, I) d p-I T=\frac{I\left(a-\frac{c}{1+\delta}\right)^{2}(2+I)}{B(I+1)^{2}}-I T .
$$

The welfare effects of integration consists of two parts. First, there is the standard effect of market integration for fixed levels of training (i.e., $\left.W_{2 J}-2 W_{J}\right)$. Second, there is the effect of moving from a training equilibrium to a no-training equilibrium (or vice versa) for given levels of integration (i.e., the comparison of $W_{I}^{T}$ and $W_{I}^{N T}$ for $I=J$ and $I=2 J$, respectively).

Lemma 1 Suppose (11) and (12) hold and hence the training equilibrium exists. Then $W_{I}^{T} \geq W_{I}^{N T}$ provided

$$
\begin{aligned}
\pi(2, I ; I)-\pi(1, I ; I)+\pi(0, I-1 ; I)+ & \frac{1}{I} \int_{P_{I}(T)}^{a} X(p, I) d p \geq \\
& \pi(0,0 ; I)+\frac{1}{I} \int_{P_{I}(0)}^{a} X(p, I) d p .
\end{aligned}
$$

\footnotetext{
${ }^{18}$ The extension to heterogeneous countries is straightforward.
} 
Proof. See Appendix 2.

As a price reduction increases the consumer surplus, a sufficient condition for (21) to hold is therefore

$$
\pi(2, I ; I)-\pi(1, I ; I)+\pi(0, I-1 ; I) \geq \pi(0,0 ; I) .
$$

After tedious calculations, this leads to

$$
\begin{aligned}
& I^{2}\left[c \delta\left(1+2 \delta^{2}+2 \delta\right)\right]+I[\left.3 c \delta(1+2 \delta)-2 a \delta\left(1+\delta^{2}+3 \delta\right)\right]+ \\
& 2\left[a-c-4 c \delta(1+\delta)+a \delta\left(5+4 \delta^{2}+8 \delta\right)\right] \geq 0
\end{aligned}
$$

The condition holds, for instance, for large $I$ or for $\delta \approx 1$.

\subsection{Integration with Unchanged Training Behavior}

Now suppose integration does not affect training.

Proposition 8 If integration does not affect training behavior, it

(i) increases welfare;

(ii) raises wages of trained workers for sufficiently large values of $J$

(iii) reduces gross profits.

Proof. See Appendix 2.

Intuitively, without training effects, the only impact of integration on aggregate welfare is the price effect, which benefits consumers and hurts producers, but is positive in the aggregate. Note, however, that firms not only suffer from lower prices, but also from higher wages. This wage effect is consistent with Feenstra and Hanson (2001) who provide evidence for an increase of skilled wages as a result of globalization. The effect results from an increase in labor demand brought about by integration: Increasing product market competition makes trained employees more valuable. 


\subsection{Integration Fosters Training}

Now suppose integration induces training equilibria.

Proposition 9 Suppose that, for $I=J$, no training equilibrium exists, but for $I=2 J$ it does. Suppose integration induces training. Then:

(i) Prices fall.

(ii) If (21) holds for $I=2 J$, welfare increases.

(iii) Even if (21) does not hold, welfare only falls if firms switch to a Paretodominated training equilibrium as a result of integration. ${ }^{19}$

Proof. See Appendix 2.

As discussed in subsection 5.1, (21) holds for $I=J$ if $J$ is large. Thus, integration fosters welfare in this case. If integration induces training, both the competition effect of integration described in Proposition 8 and the effect of lower costs work towards lower prices.

\subsection{Integration Destroys Training}

When integration destroys training, the welfare effects are ambiguous. Apart from the obvious fact that reductions in training expenses have a positive ceteris paribus effect on welfare, there are ambiguous price effects. The absence of training increases marginal costs, but competition reduces markups.

Proposition 10 Suppose that a training equilibrium exists and is selected for $I=J$, but not for $I=2 J$.

(i) Prices fall as a result of integration if and only if

$$
a>A^{*}:=\frac{c}{1+\delta}(1+2 \delta(J+1)) .
$$

(ii) If $a>A^{*}$, integration increases welfare.

\footnotetext{
${ }^{19}$ We refer to Pareto-dominance with respect to the set of firms here.
} 
Proof. See Appendix 2.

If $a>A^{*}$, the mark-up reduction resulting from integration dominates over the higher marginal costs because of the absence of training. As prices are lower and training costs are saved, welfare must increase. If $a<A^{*}$, however, integration may reduce welfare. Intuitively, the higher marginal costs after integration outweigh the lower mark-up and the savings in training expenses. Figure 4 illustrates this possibility for our standard parameter values $a=10, c=1, B=1$ in the case $\delta=0.9: \theta(J)$ and $\theta(2 J)$ are the net training incentives before and after integration, respectively. $\Delta W(J)$ denotes the welfare loss per worker that is not trained due to integration (gross of training costs $)$, that is $\Delta W(J)=\left(2\left(W_{J}^{T}+J T\right)-W_{2 J}^{0}\right) / 2 J$. For $J_{\min }<J<$ $J_{\max }$, integration destroys training for all $T \in[\theta(2 J), \theta(J)]$. At the same time, for those $J$ and $T$ that are in the shaded area, we have $T<\theta(J)<$ $\Delta W(J)$, such that the welfare losses outweigh the savings in training costs. Therefore, for these parameters, whenever integration destroys training, this reduces welfare.

- Figure 4 about here -

\section{Different Training Systems}

Until now we have considered the impact of globalization when firms in both countries have access to the same training technologies. Countries differ, however, in this respect (Ryan 2001). We therefore ask how global competition between countries with different training systems affects training incentives, focussing on apprenticeship systems of the German type. The existing literature largely concludes that firms are willing to pay a share of the training costs, although the apprentices mainly acquire general skills. ${ }^{20}$

The Systems Competition Game (SCG) is described as follows. We suppose country 1 has an apprenticeship system where there are $I_{1} \geq 2$ firms in

\footnotetext{
${ }^{20}$ See Franz and Soskice 1995, Harhoff and Kane 1997, Acemoglu and Pischke 1998, Euwals and Winkelmann 2001, Clark and Fahr 2001.
} 
the market who all train their workers as in the $M W G$, whereas in country 2 firms use workers whose training is publicly funded, so that there are $I_{2}$ firms with marginal costs of $c-\varepsilon, \varepsilon \geq 0 .{ }^{21}$ The product market is integrated. Finally, we assume that labor is mobile only within national borders. Firms from countries 1 and 2 compete in a global market place. Profits of firms in country 1 are described by the notation $\tilde{\pi}_{i}\left(t_{i}, G ; I\right)$ with the same conventions as in Section 3.1. $\tilde{\pi}_{i}\left(t_{i}, G ; I\right)$ is the profit of a firm $i$ if it has $t_{i}$ trained workers, and $G-t_{i}$ trained workers are employed by competitors; similarly, we introduce for $\widetilde{A P}(t, I ; I)$ and $\widetilde{M P}(t, I ; I)$ and use these quantities to modify Assumption 1. Finally, we shall compare the SCG with the reference case of autarky in country 1 , for which a training equilibrium exists if (11) holds with $I=I_{1}$.

Proposition 11 A training equilibrium in the $S C G$ exists if the following conditions hold:

$$
\begin{gathered}
2 \tilde{\pi}\left(1, I_{1} ; I\right)-\tilde{\pi}\left(2, I_{1 ; I}\right)-\tilde{\pi}\left(0, I_{1}-1 ; I\right)>T ; \\
\widetilde{M P}(0, I-1 ; I) \geq \widetilde{M P}(1, I-1 ; I)
\end{gathered}
$$

The proof is analogous to Proposition 2.

We now present some simple illustrations for the effects of international competition between training systems. ${ }^{22}$ We distinguish two cases. In the first case, country 1 faces competition by $I_{2}$ firms in country 2 that each have one trained worker, that is, $c_{i}=\frac{1}{\delta+1}$ or equivalently, $\varepsilon=c \frac{\delta}{\delta+1}$. In the second case, country 2 has only low-skilled workers, that is, $\varepsilon=0$. Parameter values are $a=10, b=1, c=1, \delta=0.9$.

- Figure 5 about here -

\footnotetext{
${ }^{21}$ Hence, $\varepsilon$ is the net cost effect which incorporates the productivity effect of trained workers and associated wage costs. When firms have to pay taxes to finance public vocational schools, such tax effects would have to be included.

${ }^{22}$ In Appendix 3, we list all relevant payoff functions.
} 
Figure 5 shows training incentives as functions of $I_{1}$ and $I_{2}$ for publicly funded training. Similarly, Figure 6 gives training incentives for competition from low-skill countries.

- Figure 6 about here -

In the latter case, the non-monotonicity familiar from our earlier models reoccurs. For sufficiently small $I_{2}$, product market integration may increase incentives to train. For larger values of $I_{2}$, integration unambiguously lowers benefits from training. However, Figure 5 suggests that the positive effects of integration for small values of $I_{2}$ may disappear altogether. Hence, systems competition may be an even larger threat to apprenticeship systems than the integration of product markets where all firms are subject to the same training technologies.

Euwals and Winkelmann (2001) explain the decline in the number of apprentices over the last decade in Germany with demographic and compositional factors. Our theoretical analysis suggests that globalization might have accelerated the decline of the apprenticeship system. With such forces undermining the sustainability of the system, education policy faces the difficult decision of whether or not to give incentives to stabilize the system.

\section{Extensions and Conclusions}

Our paper makes the following main points: First, the effects of product market integration on training incentives are positive when the initial market concentration is high and negative when it is low. Second, when integration destroys training, the net effect on welfare may be negative. Third, if trained labor is homogeneous, labor market integration has essentially no effect on training. Finally, systems competition might undermine training systems.

So far our approach uses several simplifying assumptions. For instance, we have treated training as a zero-one decision. It is perceivable that a 
continuous treatment of training levels would lead to qualitative changes of the results.

Another simplification concerns the assumption that all fixed costs are sunk with entry which, as detailed in Appendix 1, implies that integration does not affect the total number of firms in the market: The number of firms in the integrated market is simply the sum of firms in each market. Alternatively, one could consider a setting where there are also substantial fixed costs that are not sunk. In this case, post-integration exit would have potential effects on the training decisions of the remaining firms. 


\section{Appendices}

\subsection{Appendix 1: Endogenizing the number of firms}

Using the example of the IWG, we now show how the number of firms in the market can be endogenized. To this end, we distinguish between the pre-integration game and the post-integration game. In the first stage of the pre-integration game, firms decide whether to incur entry costs $E$, which we assume to be the only fixed costs of production. The remaining two stages are exactly as the first and second stages of the $I W G$ in the main text.

The pre-integration game determines the number of active firms in the two markets at the time that integration takes place. We assume that integration is an unanticipated shock to the firms. In the post-integration game, the firms remaining from the pre-integration game are the incumbents. In addition, there are potential entrants. In the first stage of the game, the incumbents who have already incurred the sunk entry costs decide whether they want to remain in the market or exit at zero costs. At the same time, the potential entrants decide whether they want to incur the fixed costs of entering the world market. As in the pre-integration game, the second and third stage of the post-integration game are entirely analogous to the first and second stage of the IWG. We shall now refer to the subgame consisting of these two stages as the training subgame.

Lemma 2 Suppose that, in the training subgame there are I firms in the market. Then there is an equilibrium of the training subgame such that $G^{I}$ firms train, where $G^{I}$ is defined as the maximal integer for which

$$
\pi_{i}\left(1, G^{I} ; I\right)-\pi_{i}\left(0, G^{I}-1 ; I\right) \geq T .
$$

Further, there is no equilibrium with more than $G^{I}$ firms training.

Proof. For any integer $G^{I}$ satisfying (22), there is no incentive for a firm to deviate by not training. As $G^{I}$ is the maximal number with property $(22)$, it is also not a profitable deviation for a firm that does not train in 
the proposed equilibrium to deviate and train. Also, clearly, if $G>G^{I}$ firms train, a firm that trains can profitably deviate by not training.

Clearly, whenever $G^{I}<I$, there are multiple equilibria such that $G^{I}$ firms train. For definiteness, we suppose the firms that train are indexed $1, \ldots, G^{I}$. Moreover, in the post-integration game, in any subgame where there is entry resulting in $I>G^{I}$ firms, we assume that only incumbents train. Lemma 2 can now be applied to justify our assu,ption in the main text that the total number of firms in the world market is unaffected by integration.

Lemma 3 Suppose $I=J$ is the number of firms in any subgame-perfect equilibrium of the pre-integration game in each market and $G^{J}=J$. Further suppose

$$
\pi_{i}(0,0,2 J+1) \leq \pi_{i}(0, J, J+1) .
$$

Then the number of firms in any subgame-perfect equilibrium of the postintegration game in the world market is $I=2 J$, that is, the incumbents remain in the market and there is no entry.

Proof. Clearly, in an SPE of the post-integration game, no incumbent will exit because by staying in the market and abstaining from training, a non-negative profit can be guaranteed as all fixed costs are assumed to be sunk. Thus, $I \geq 2 J$. Hence, suppose there are at least $2 J$ firms in the market. For the pre-integration equilibrium to satisfy $I=J$ and $G^{J}=J$, it is necessary that no additional firm finds entry profitable, no matter whether it invests in training or not. Therefore, the following conditions hold:

$$
\begin{aligned}
\pi_{i}(0, J, J+1) & <E \\
\pi_{i}(1, J+1, J+1) & <E+T .
\end{aligned}
$$

We now show that entry is unprofitable in the post-integration game if (23), (24) and (25) hold. First consider the case

$$
\pi_{i}(1,2 J, 2 J+1)-\pi_{i}(0,2 J-1,2 J+1) \geq T .
$$


In this case, all $2 J$ incumbents train in the post-integration game if deviation from the equilibrium with $I=2 J$ firms would occur and one additional firm would enter. Then there will be no entry if the following conditions hold simultaneously:

$$
\begin{aligned}
\pi_{i}(0,2 J, 2 J+1) & <E \\
\pi_{i}(1,2 J+1,2 J+1) & <E+T .
\end{aligned}
$$

Using (4), both conditions are implied by (24) and (25).

Next suppose (26) does not hold. Then only $G^{2 J+1}<2 J$ firms will train if an entrant enters the market. Therefore, no additional firm will find entry without training profitable if

$$
\pi_{i}\left(0, G^{2 J+1}, 2 J+1\right)<E
$$

The left-hand side is bounded above by $\pi_{i}(0,0,2 J+1)$. Because $\pi_{i}(0, J, J+1)<E$ by $(24)$ and $\pi_{i}(0,0,2 J+1)<\pi_{i}(0, J, J+1)$ by $(23)$, $\pi_{i}(0,0,2 J+1)<E$. As $\pi_{i}\left(0, G^{2 J+1}, 2 J+1\right) \leq \pi_{i}(0,0,2 J+1),(27)$ holds. Also, given that $G^{2 J+1}$ incumbents are training, (27) and the condition that $\pi_{i}\left(1, G^{2 J+1}+1,2 J+1\right)-\pi_{i}\left(0, G^{2 J+1}, 2 J+1\right)<T$ imply that entry with training is not profitable.

Condition (22) is sufficient rather than necessary for the conclusion to hold. We used (22) to give a sufficient condition for (27) in terms of primitives of the model; obviously, (27) is a much less demanding requirement than (22). Also, (22) obviously holds whenever the negative effect from having $2 J+1$ rather than $J+1$ firms in the market dominates over the positive effect from having 0 rather than $J$ competitors with trained workers. Specifically therefore, condition (23) holds when the training effects on costs are small, that is $\delta$ is high. 


\subsection{Appendix 2: Proofs}

\subsubsection{Proof of Corollary 1}

Simple calculations show that

$$
\frac{\partial(\Delta \pi)}{\partial I}=\frac{\delta c I}{B(I+1)^{3}(1+\delta)^{2}}\left[\delta c\left(4-3 I-I^{2}\right)+4(a-c)(1+\delta)\right],
$$

which is positive if and only if

$$
\delta c\left(4-3 I-I^{2}\right)+4(a-c)(1+\delta)>0 .
$$

There is a unique $I^{*}>0$ for which the left-hand side is 0 . For $I \rightarrow 0$, the left hand side is positive; for sufficiently large $I$ it is negative.

\subsubsection{Proof of Proposition 2}

First, we show that, if (13) and (9) hold, there is indeed an equilibrium such that each worker is offered $w^{*}$ by each firm, and therefore each firm employs exactly one worker at the end of the turnover game. By (13), the gross profit reduction from having no trained worker instead of one outweighs the reduction in wage payments $w^{*}$, so that reducing the wage offer is not a profitable deviation. Conversely, to attract $t_{i}-1$ more trained workers, a firm has to offer them wages slightly above $w^{*}$, leading to gross profits $\pi_{i}\left(t_{i}, I ; I\right)$ and wages of approximately $\pi_{i}(2, I ; I)-\pi_{i}(1, I ; I)$ per worker. The relevant non-deviation condition is thus

$$
\pi_{i}\left(t_{i}, I ; I\right)-\pi_{i}(1, I ; I) \leq\left(t_{i}-1\right)\left[\pi_{i}(2, I ; I)-\pi_{i}(1, I ; I)\right] \text { for } t_{i} \geq 2
$$

Clearly, (9) and (28) are equivalent.

Next, suppose that, in equilibrium, one firm (say firm 1) has at least two workers, whereas some other firms have none. By conditions (13) and (9), firm 1 is willing to pay at most $\pi_{i}(1, I ; I)-\pi_{i}(0, I ; I)$ on average for each of its workers. As the firms from which firm 1 has poached the workers would also be willing to pay that quantity to retain their workers, the amount does 
not suffice to poach the workers.

(b) Suppose that $M P(1, I ; I)>M P(0, I ; I)$, so that (13) does not hold. First, a symmetric training equilibrium requires that wages are at most $M P(0, I ; I)$; otherwise firms could profitably deviate by reducing the wage so that they do not employ a worker. As $M P(1, I ; I)>M P(0, I ; I)$, with such a proposed equilibrium wage, firms could profitably deviate by offering a slightly higher wage, so as to employ a second worker. Thus, any subgame equilibrium must involve an asymmetric worker distribution. If firm $i$ has smaller net profits, it can deviate by offering slightly higher wages to the workers of firm $j$, so that these workers go to firm $i$ and it earns approximately the higher net profits of firm $j .^{23}$

\subsubsection{Proof of Proposition 3}

If each firm offers $w^{*}$, all firms receive net profits $\pi(0, I-1 ; I)$. First, consider deviation incentives for firms that employ a trained worker in equilibrium. Such firms earn gross profits $\pi(1, I-1 ; I)$, from which $M P(0, I-1 ; I)$ have to be deducted. Downward deviations (below $w^{*}$ ) for such firms would not be profitable. They would not have to pay wages, but gross profits would drop to $\pi(0, I-1 ; I)$. By increasing wages slightly above $w^{*}$, a firm could obtain additional workers. Gross profits from hiring $t_{i}-1$ workers would be $\pi\left(t_{i}, I-1 ; I\right)$ rather than $\pi(1, I-1 ; I)$. Subtracting wage payments, the net gain from deviation is thus approximately

$\pi\left(t_{i}, I-1 ; I\right)-\pi(1, I-1 ; I)-\left(t_{i}-1\right)(\pi(1, I-1 ; I)-\pi(0, I-1 ; I)) \leq 0$.

By (10), this expression is non-positive. Next consider the incentives of the firm without a worker to increase its wage offer slightly. This would increase gross profits by $\pi(1, I-1 ; I)-\pi(0, I-1 ; I)$, but increase wages by approximately the same amount. More generally, increasing wage offers to any number $\left(t_{i}-1\right)$ of workers is not profitable by $(10)$.

\footnotetext{
${ }^{23}$ Note that no other firm offers the same wages in the candidate equilibrium since otherwise workers would not stay at firm $j$.
} 


\subsubsection{Proof of Proposition 4}

Firms' profits in equilibrium are given by $\pi(0,0 ; I)$. When one firm deviates to $g_{i}=1$, the trained worker will end up at the deviating firm in the turnover game according to our tie-breaking rule. As the wage for the trained worker will be bid up to $\pi(1,1 ; I)-\pi(0,1 ; I)$, all firms will end up with a net payoff of $\pi(0,1 ; I)$. Hence, the deviating firm would have a long-term payoff of $\pi(0,1 ; I)-T$. Thus, the deviation is not profitable.

\subsubsection{Proof of Proposition 6}

(i) is immediate.

(ii) follows because it can be shown that $\alpha<0$.

(iii) $\theta^{\prime}(I)=\frac{\gamma+2 \beta I-\gamma I+3 \alpha I^{2}+\alpha I^{3}}{\left(2 I+I^{2}+1\right)(I+1)}$. It can be shown that $\gamma<0$. Thus $\theta^{\prime}(0)<0$. As the numerator of $\theta^{\prime}(I)$ has at most three zeroes, (ii) implies that it has at most two zeroes on $[0, \infty]$.

\subsubsection{Proof of Lemma 1}

Condition (11) can be rewritten as:

$$
\pi(1, I ; I)-T \geq \pi(2, I ; I)-\pi(1, I ; I)+\pi(0, I-1 ; I) .
$$

Thus, (1) implies

$$
\pi(1, I ; I)+\frac{1}{I} \int_{P_{I}(T)}^{a} X(p, I) d p-T>\pi(0,0 ; I)+\frac{1}{I} \int_{P_{I}(0)}^{a} X(p, I) d p .
$$

\subsubsection{Proof of Proposition 8}

(i) If there is a training equilibrium before and after integration, welfare increases if and only if $P_{2 J}(T)<P_{J}(T)$, as $W_{2 J}^{T}>W_{J}^{T}$ reduces to a simple comparison of the sum of gross producer and consumer surplus before and after integration. From (2), $P_{2 J}(T)<P_{J}(T)$ is obvious. The proof for the 
equilibrium without training is analogous.

(ii) Calculating wages $w^{*}(I)$ as a function of $I$ yields

$$
\begin{aligned}
w^{*}(I) & =M P(1, I ; I)=\pi^{I}(2, I ; I)-\pi^{I}(1, I ; I) \\
& =\frac{I}{B(I+1)^{2}}\left[\left(a+I c \frac{\delta}{(2 \delta+1)(\delta+1)}-c \frac{1-\delta}{\delta+1}\right)^{2}-\left(a-\frac{c}{\delta+1}\right)^{2}\right] .
\end{aligned}
$$

For sufficiently large values of $I, \partial w^{*} / \partial I>0$. Therefore $w^{*}(J)<w^{*}(2 J)$ if $J$ is sufficiently large.

(iii) follows immediately from

$$
\frac{\partial \pi^{I}(1, I ; I)}{\partial I}=\left(a-\frac{c}{\delta+1}\right)^{2} \frac{1-I}{B(I+1)^{3}}<0 .
$$

\subsubsection{Proof of Proposition 9}

(i) $P_{2 J}(T)<P_{J}(0)$ as $P_{2 J}(T)<P_{J}(T)$ and $P_{J}(T)<P_{J}(0)$.

(ii) Integration increases welfare, if and only if,

$2 J \pi^{2 J}(1,2 J ; 2 J)+\int_{p_{2 J}(T)}^{a} X(p, 2 J) d p-2 J T>2 J \pi^{J}(0,0 ; J)+\int_{p_{J}(0)}^{a} X(p, 2 J) d p$.

Inserting $I=2 J$ into Condition (11) with $I=2 J$,

$$
\pi^{2 J}(1,2 J ; 2 J)-T \geq \pi^{2 J}(2,2 J ; 2 J)-\pi^{2 J}(1,2 J ; 2 J)+\pi^{2 J}(0,2 J-1 ; 2 J) .
$$

Using (21) with $I=2 J$, this implies

$$
\pi^{2 J}(1,2 J ; 2 J)-T \geq \pi^{2 J}(0,0 ; 2 J) .
$$

Welfare therefore increases if

$$
\int_{p_{2 J}(T)}^{a} X(p, 2 J) d p>\int_{p_{2 J}(0)}^{a} X(p, 2 J) d p
$$

This follows from $p_{2 J}(T)<p_{2 J}(0)$.

(iii) Follows immediately from (i). 


\subsubsection{Proof of Proposition 10}

(i) By (2),

$$
p_{J}(T)=\frac{a}{J+1}+\frac{J c}{(J+1)(\delta+1)}
$$

and

$$
p_{2 J}(0)=\frac{a}{2 J+1}+\frac{2 J c}{2 J+1}
$$

Simple rearrangements show that $p_{2 J}(0)<p_{J}(T)$, if and only if, $a<A^{*}$.

$$
a>A^{*} \equiv \frac{c}{1+\delta}(1+2 \delta(J+1))
$$

(ii) follows from (i) since integration reduces prices and training costs.

\subsection{Appendix 3: Gross Payoffs for the MWG}

We now compile the formulas that we use for the numerical analysis:

$$
\begin{aligned}
\pi_{i}(0, I ; I) & =\frac{I}{B(I+1)^{2}}\left(a-I c \frac{\delta}{\delta+1}+c\left(-\frac{2}{\delta+1}+\frac{1}{2 \delta+1}\right)\right)^{2} ; \\
\pi_{i}(1, I ; I) & =\frac{I}{B(I+1)^{2}}\left(a-\frac{c}{\delta+1}\right)^{2} ; \\
\pi_{i}(2, I ; I) & =\frac{I}{B(I+1)^{2}}\left(a+I c\left(\frac{1}{\delta+1}-\frac{1}{2 \delta+1}\right)+c \frac{\delta-1}{\delta+1}\right)^{2} ; \\
\pi_{i}(0, I-1 ; I) & =\frac{I}{B(I+1)^{2}}\left(a-I c \frac{\delta}{\delta+1}-\frac{c}{\delta+1}\right)^{2} ; \\
\pi_{i}(1, I-1 ; I) & =\frac{I}{B(I+1)^{2}}\left(a+c\left(\frac{\delta-1}{\delta+1}\right)\right)^{2} ; \\
\pi_{i}(2, I-1 ; I) & =\frac{I}{B(I+1)^{2}}\left(a+I c\left(\frac{1}{\delta+1}-\frac{1}{2 \delta+1}\right)+c \frac{2 \delta-1}{\delta+1}\right)^{2} .
\end{aligned}
$$

\subsection{Appendix 4: Necessary Conditions for Training}

First we show that, if (11) is violated but the "no-turnover" condition (13) holds, then the training equilibrium cannot exist. Second, if (13) is also 
violated, the training equilibrium cannot exist if we impose an additional plausible condition.

Proposition 12 Suppose condition (11) does not hold, whereas (13) does. Then there is no training equilibrium.

Proof. By Proposition 2 and condition (13), if $g_{i}=1$ for all $i \in\{1, \ldots, I\}$, there is no turnover in the second stage, and each firm obtains a long-term payoff of $2 \pi(1, I ; I)-\pi(2, I ; I)-T$. Deviating to "no training", a firm would obtain $\pi(0, I-1 ; I)$ by Lemma 3 . If condition (11) is violated, the deviation incentive is therefore positive.

Next we consider the case that (13) does not hold. By part (b) of Proposition 2, when all firms have trained a worker, each firm's net payoff will be bounded above by the gross payoff of a firm with no trained worker that faces I trained workers employed by competitors. If a firm deviates to no training, it will employ no workers in the equilibrium of period 2. Therefore, it will have a net payoff that is the product market payoff of a firm that faces $I-1$ trained workers. The following condition therefore appears to be plausible.

Condition ICW (Increasing Competition for Workers): If (13) is violated, a firm earns lower net profits in the training game where each of the I firms trains than when it deviates to "No Training" while all other firms train.

Therefore, if (ICW) holds, even if training costs were zero, firms would prefer not to train. Thus, clearly there can be no training equilibrium.

However, there is a snag in the argument. We have not yet said anything about the distribution of workers in the subgames that we are comparing. The argument is sound if, in the subgame with $I$ workers, $(I-1)$ workers are distributed exactly as in the subgame with $(I-1)$ workers, and the $I$ th worker is added to one firm. However, if, in the equilibrium of the game with $I$ trained workers, there is at least one competitor of firm $i$ that has a smaller number of trained workers than in the game with $I-1$ trained workers, firm $i$ 's payoff may be higher in the game with more trained workers, and training 
could in principle be an equilibrium. ${ }^{24}$ However, such an equilibrium would require that the marginal productivity of a worker changes massively from $I$ to $I-1$. We have not found an example where this occurs.

\subsection{Appendix 5: The Systems Competition Game}

This Appendix contains the Payoffs that were used in the calculations in Section 6.

$$
\begin{aligned}
\tilde{\pi}_{i}\left(1, I_{1} ; I_{1}\right) & =\left(\alpha+\frac{\delta c}{\delta+1}+I_{2} \frac{\delta c}{\delta+1}-I_{2} \varepsilon\right)^{2}, \\
\tilde{\pi}_{i}\left(2, I_{1} ; I_{1}\right) & =\left(\alpha+I_{1} c\left(\frac{1}{\delta+1}-\frac{1}{2 \delta+1}\right)+2 c \frac{\delta}{\delta+1}+I_{2} c \frac{2 \delta}{2 \delta+1}-I_{2} \varepsilon\right)^{2}, \\
\tilde{\pi}_{i}\left(0, I_{1}-1 ; I_{1}\right) & =\left(\alpha-I_{1} c \frac{\delta}{\delta+1}+c \frac{\delta}{\delta+1}-I_{2} \varepsilon\right)^{2} .
\end{aligned}
$$

\subsection{Appendix 6: Figures and Tables}

Table 1: Game Structure

Period 1: Firms $i=1, \ldots, I$ choose training levels $g_{i}$.

Period 2: (i) Firms choose wage offers $w_{i, j}\left(g_{1}, \ldots, g_{I}\right)$.

(ii) Workers choose between employers, thus determining the numbers $t_{i}$ of trained workers.

Period 3: Product market competition with gross profits $\widetilde{\pi}_{i}\left(t_{1}, \ldots, t_{I} ; I\right)$.

\footnotetext{
${ }^{24}$ For instance, by (1), if a firm without trained workers has two competitors, it has strictly higher profits when each competitor has one trained worker than when one competitor has one trained worker and the other has two. However, one can show that if three employees work in one other firm, payoffs are higher than when each of the two competitors has one trained worker if $\delta>\frac{1}{3}$.
} 


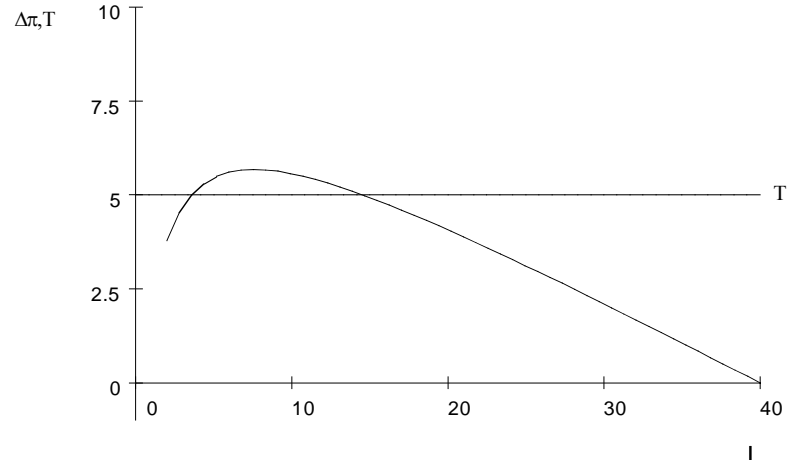

Figure 1: Training Incentives with Immobile Workers

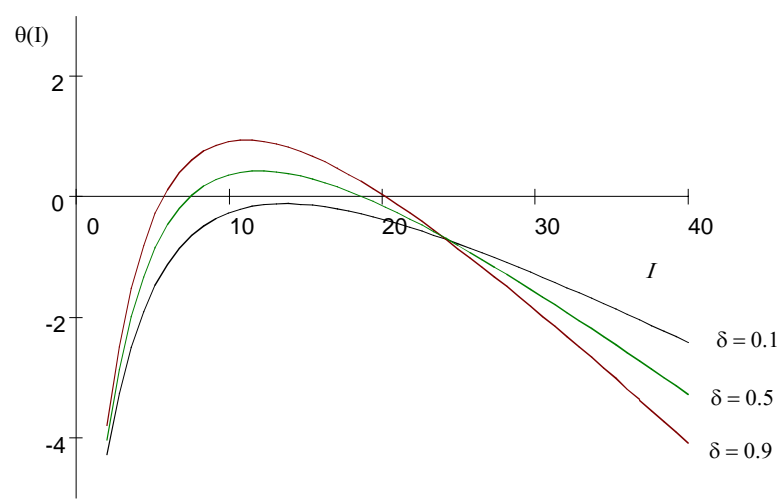

Figure 2: Net Training Incentives 


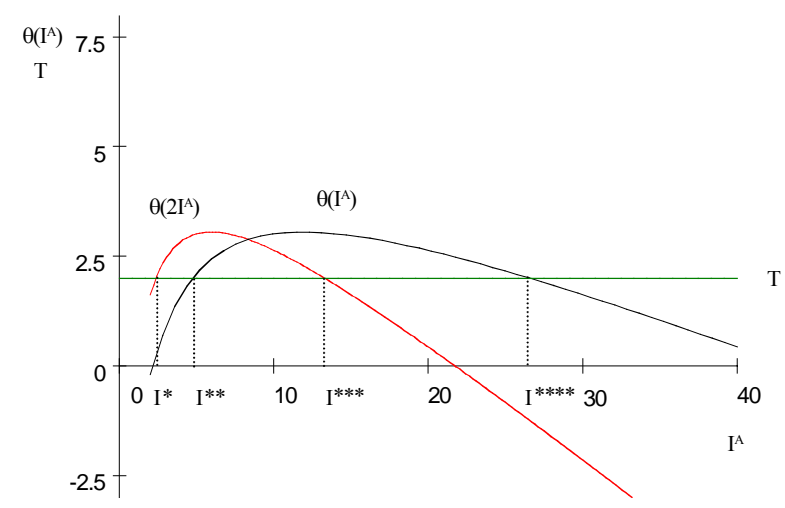

Figure 3: The Effects of Integration

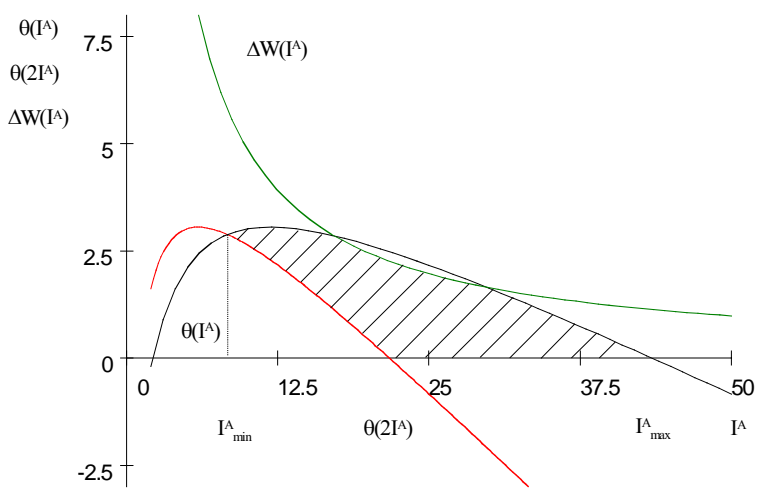

Figure 4: Welfare and the Destruction of Training Equilibria 


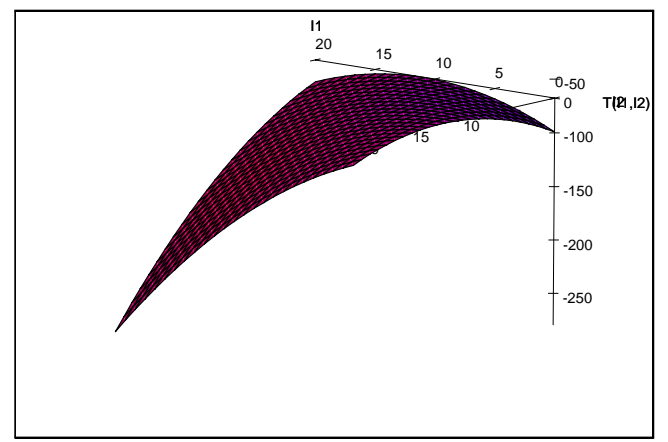

Figure 5: Systems Competition, $\delta=0.9$

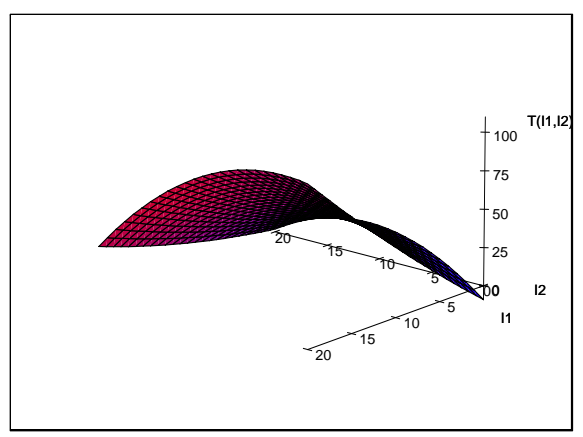

Figure 6: Low-Skill Competition, $\delta=0.9$ 


\section{References}

Abe, Y. "Specific Capital, Adverse Selection and Turnover: A Comparison of the United States and Japan" Journal of the Japanese and International Economies, Vol. 8 (1994), 72-294.

Acemoglu, D. "Training and Innovation in an Imperfect Labor Market" Review of Economic Studies, Vol. 64 (1997), 445-464.

Acemoglu, D. and Pischke, J.S. "The Structure of Wages and Investment in General Training" National Bureau of Economic Research, Working Paper No. 6357 (1998).

Acemoglu, D., and J.S. Pischke (1998), "Why Do Firms Train? Theory and Evidence", Quarterly Journal of Economics, 113 (1), 79-119.

Acemoglu, D. and Pischke, J.S. (1999), "Beyond Becker: Training in Imperfect Labour Markets" Economic Journal 109, F112-F142.

Acemoglu, D. "Technical Change, Inequality, and the Labor Market", Journal of Economic Literature, (2002), 40 (1), 7-72

Becker, G. "Human Capital" University of Chicago Press, (1964).

Cartiglia, F. "Credit Constraints and Human Capital Accumulation in the Open Economy", Journal of International Economics, (1997) Vol. 43, 221-36 Chang, C. and Wang, Y. "Human Capital Investment under Asymmetric Information: The Pigovian Conjecture Revisited " Journal of Labor Economics, Vol. 16 (1996), 505-519.

Chuang, Y.C. "Learning by Doing, Technology Gap and Growth", International Economic Review, 39, 697-722 (1998).

Chuang, Y.C. "Human Capital, Exports, andEconomic Growth: A Casuality Analysis for Taiwan, 1952-1995", Review of International Economics, 8, pp. 712-720 (2000).

Clark, D., and R. Fahr (2001), "The Promise of Workplace Training for NonCollege-Bound Youth: Theory and Evidence from German Apprenticeship", IZA Discussion Paper, No. 378.

Euwals, R. and R. Winkelmann (2001), "Why Do Firms Train? Empirical Evidence on the First Labour Market Outcomes of Graduated Apprentices", 
IZA Discussion Paper No. 319.

Findlay, R. and H. Kierzkowski (1983), "International Trade and Human Capital: A Simple General Equilibrium Model", Journal of Political Economy $91,957-978$.

Feenstra, R., Hanson, G. "Global Production Sharing and Rising Inequality: A Survey of Trade and Wages", (2001), NBER Working Paper No. 8372.

Franz, W. and Soskice, D. "The German Apprenticeship System" in F. Buttler et al.: Institutional Frameworks and Labor Market Performance. Comparative Views on the German and U.S. Economies, London, Routledge, 208-234 (1995).

Gersbach, H. and Schmutzler, A. "A Product Market Theory of Training and Turnover in Firms", CEPR Discussion Paper No. 3940 (2003).

Glaeser, E. "Two Essays on Information and Labor Markets", University of Chicago, (1992), Ph.D. thesis.

Harhoff, D., and T.J. Kane (1997), "Is the German Apprenticeship System a Panacea for the US Labour Market?", Journal of Population Economics 10, 171-196.

Katz, L. and David Autor (1999), "Changes in the Wage Structure and Earnings Inequality" in Orley Ashenfelter and David Card, eds., Handbook of Labor Economics. Vol. 3A, Amsterdam: Elsevier, 1463-1555.

Katz, E. and Zidermann, A. "Investment in General Training: The Role of Information and Labour Mobility" Economic Journal, (1990), 1147-1158.

Kim, S., Kim, Y. "Growth Gains from Trade and Education", Journal of International Economics, (2000), Vol. 50, 519-45.

Mincer, J. "Schooling, Experience, and Earnings" New York: Columbia University Press, (1974).

Motta M. "Competition Policy, Theory and Practice", Cambridge University Press.

Prendergast, C. "Career Development and Specific Human Capital Collection" Journal of the Japanese and International Economies, Vol. 5 (1992), 207-227. 
Rodrik, D. "Has Globalization Gone Too Far?", (1997), Institute for International Economics.

Ryan, P. (2001), "The School-to-Work Transition: A Cross-National Perspective", Journal of Economic Literature, 39 (1), 34-92.

Scherer, F.M., Ross, D. "Industrial Market Structure and Economic Performance", Houghton Mifflin Company, Boston

Stokey, N. (1991) "Human Capital, Product Quality, and Growth", Quarterly Journal of Economics 106, 587-616.

Stokey, N.L. (1996) "Free Trade, Factor Returns, and Factor Accumulation", Journal of Economic Growth, 1, pp. 421-47.

Teulings, C. N. (2000), "Aggregation Bias in Elasticities of Substitution and the Minimum Wage Paradox", International Economic Review, 41 (2), 359398.

Vives, X. "Innovation an Competitive Pressure" Paper given at the CEPR Workshop on International Competition Policy (2003).

Wood, A. and C. Ridao-Cano (1999) "Skill, Trade and International Inequality", Oxford Economic Papers, 51, pp. 89-119. 